Diabetologia 10, 119-130 (1974)

(C) by Springer-Verlag 1974

\title{
Inter-Relationship between Insulin Secretion and Plasma Free Fatty Acid and Triglyceride Transport Kinetics in Maturity Onset Diabetes and the Effect of Phenethylbiguanide (Phenformin)
}

\author{
A.H. Kissebah, P.W. Adams and V. Wynn \\ Alexander Simpson Laboratory for Metabolic Research, St. Mary's Hospital Medical School, London, W. 2 \\ Received: April 28, 1973, and in revised form: November 22, 1973
}

\begin{abstract}
Summary. The plasma free fatty acid and triglyceride transport kinetics in 16 non-obese and 7 obese maturity onset diabetics with hypertriglyceridaemia have been compared with results obtained in 27 control subjects. Changes in glucose and insulin responses were evaluated in relation to the lipid parameters. All the diabetics showed elevated plasma FFA levels and turnover rates. In the non-obese diabetics the plasma triglyceride turnover rate was within the normal range and their hypertriglyceridaemia was due to impaired triglceride clearance. In the obese diabetics the plasma triglyceride turnover rate was increased and they also had some impairment of triglyceride clearance, so that in them a double mechanism was observed to account for their hypertriglyceridaemia. The insulin levels in the diabetics were similar to, or greater than, those found in the controls. Our results suggested that the enhanced lipolysis and impaired triglyceride clearance observed in the diabetic patients were a manifestation of insulin unresponsiveness in adipose tissue and that the changes in insulin and glucose rela-
\end{abstract}

tionship could be secondary to elevated FFA and triglyceride levels. Further confirmation was obtained by the finding of an exaggerated insulin response to a glucose challenge in normal subjects infused with Intralipid. Treatment with phenethylbiguanide (Phenformin) significantly lowered the plasma FFA and triglyceride concentration in both diabetic groups. This was associated with normalisation of both plasma FFA turnover and triglyceride clearance. It also reduced the triglyceride turnover rate to the normal range in the obese diabetics. These changes were associated with a fall of plasma glucose and insulin levels to within the normal range. These results suggested an effect of Phenformin in reducing the rate of lipolysis leading to improved glucose tolerance.

Key words: Maturity onset diabetes, kinetic measurements, free fatty acid (FFA), triglyceride (TG), insulin, post-heparin lipolytic activity (PHLA), hypertriglyceridaemia, turnover rate, influx rate clearance, oral glucose tolerance test (O.G.T.T.).
The structural changes of atherosclerosis are, for practical purposes, probably irreversible. The most important therapeutic goal therefore is to prevent their development. Diabetics with vascular complications often have elevated levels of plasma lipids, including triglycerides [2]. Hypertriglyceridaemia has received increasing attention recently as a causative factor in atherogenesis in man $[9,25,10]$.

Cross-sectional prevalence studies, on the other hand, have shown a correlation between the development of atheroselerosis in diabetics and the degree of insulinaemia observed in these patients $[49,28]$. The association of these two risk factors has been stressed in several studies $[15,19,20]$. However, the relationship between hypertriglyceridaemia and hyperinsulinaemia in diabetic subjects remains to be clarified. The current view is that these patients have difficulty in peripheral glucose disposal. In an attempt to compensate for this difficulty insulin secretion is stimulated to maintain adequate glucose uptake at tissue level. The increased availability of glucose and insulin stimulates hepatic triglyceride synthesis and produces hypertriglyceridaemia. This view is supported by the finding of a positive correlation between plasma triglycerides and immuno-reactive insulin levels $[19,20]$. This concept differs from that of Sailer et al. [43], who favour the view that the hyperinsulinaemia might be a conse- quence rather than the cause of hypertriglyceridaemia in these patients.

Unfortunately, the mechanisms involved in the control of plasma triglyceride levels in diabetics have not been clearly delineated. Knowledge of such mechanisms is of obvious importance in determining the appropriate therapy.

The aim of this work was to study the kinetios of plasma free fatty acid and triglyceride transport in patients with maturity onset diabetes and to determine the inter-relationship between insulin secretion and triglyceride levels. In addition, the effects of Phenformin (phenethylbiguanide) therapy on plasma free fatty acid and triglyceride transport kinetics have been evaluated in these patients.

\section{Subjects}

50 subjects were studied. The control group of 27 healthy subjects comprised 15 pre-menopausal female and 12 male volunteers, with normal fasting serum lipid levels and glucose tolerance. The mean age of this group was 35 (range 17-62) and all these subjects were non-obese (less than $115 \%$ of their ideal body weight obtained from data from Documenta Geigy). None were taking any drugs known to affect lipid or carbohydrate metabolism. 
23 maturity onset diabetic patients of both sexes with fasting hypertriglyceridaemia were selected. 16 were non-obese, with relative body weights less than $115 \%$ of their ideal body weight, and 7 were obese with relative body weights in excess of $115 \%$ of their ideal body weight. These patients were selected from newly diagnosed, non-ketotic diabetics referred to our clinic. Oral glucose tolerance tests were performed on the patients and those who had an abnormal response and fasting hypertriglyceridaemia were stabilized on an isocaloric diet on an outpatient basis. The isocaloric diet provided $35 \mathrm{cals} / \mathrm{kg}$ ideal body weight, of which $38 \%$ was in the form of carbohydrate, $\mathbf{4 5 \%}$ as fat and $17 \%$ protein. Two weeks later they were admitted to the Metabolic Ward for a further period of two weeks. During this period the fasting blood sugar, plasma lipids, urinary ketones (acetest), and body weights were recorded. At the end of this period the oral glucose tolerance test was repeated. Only those patients in whom glucose intolerance was substantially unchanged, plasma lipids and body weight stabilized, and who remained non-ketotic were selected for the study. $\mathrm{Ab}$ normal glucose tolerance was diagnosed when two or more of the following criteria were present: fasting plasma glucose $>100 \mathrm{mg} / 100 \mathrm{ml}, 60^{\prime}$ plasma glucose $>180 \mathrm{mg} / 100 \mathrm{ml}$, and $120^{\prime}$ plasma glucose level of $>140 \mathrm{mg} / 100 \mathrm{ml}$. Details of the ages and relative body weights of the subjects studied are shown in Tables $1 \mathrm{a}$ and $b$.

The control subjects were similarly stabilized on an isocaloric diet before testing. Kinetic measurements were then performed on both groups. Having completed these investigations the diabetic patients were treated with Phenformin 50-100 mgm b.d. for a period of 3-6 months. During this time the isocaloric diet was continued and the weights of the patients remained substantially unchanged. At the end of the treatment period the kinetic measurements were repeated.

\section{Methods}

\section{A. Measurement of Kinetics of Plasma FFA and Triglyceride Transport}

Plasma free fatty acid and triglyceride turnover rates were determined using a continuous infusion of ${ }^{14} \mathrm{C}$ labelled palmitate. The plasma free fatty acid flux was calculated from the rate of infusion of the label and plasma free fatty acid specific radioactivity at equilibrium. The plasma triglyceride turnover rate was estimated from the slope of the specific radioactivity disappearance curve of endogenously labelled triglycerides after stopping the ${ }^{14} \mathrm{C}$-palmitate infusion. The technical details and validation of this method have been presented elsewhere [31, 32]. The Appendix shows three decay curves and a comparison between the turnover values calculated using this technique, and that obtained from studies in which pre-labelled lipoprotein triglycerides were re-injected into the same subject.
I. $F F A$ turnover. After an overnight fast an indwelling catheter was inserted into a vein in both antecubital fossae and the patient was then rested for half an hour. $25 \mu$ ci of ${ }^{14} \mathrm{C}$ palmitic acid was infused at a rate of $0.2 \mu \mathrm{ci}$ per minute, using a constant delivery syringe, for $2 \mathrm{~h}$, blood samples being taken from the contralateral arm. Plasma free fatty acid turnover rate was then calculated as follows:

Turnover $(\mu \mathrm{eq} / \mathrm{min})=$ Infused dose (dpm per min)

FFA specific activity at equilibrium (dpm per $\mu \mathrm{eq})$

II. Triglyceride turnover. After stopping the labelled palmitate infusion, samples of blood were collected from the contralateral arm catheter at $30 \mathrm{~min}$ intervals for a period of $12 \mathrm{~h}$. The plasma was separated and the triglyceride specific radioactivity was determined. The specific activity time curves were plotted semi-logarithmically and the fractional turnover rate of plasma triglyceride $(\mathrm{Ka})$ was calculated, using the method of least squares. Triglyceride turnover rate (V) in $\mu \mathrm{mol} /$ $\mathrm{kg} / \mathrm{h}$ was calculated from the formula:

$$
\mathrm{V}=\mathrm{S} \times 50 \times \mathrm{Ka}
$$

where $S$ represents the serum triglyceride concentration in $\mu \mathrm{mol} / \mathrm{ml}$. In this calculation the plasma volume was considered to represent the distribution space of triglycerides and the co-efficient 50 assumes that the plasma volume is $50 \mathrm{ml} / \mathrm{kg}$ body weight.

III. Clearance of endogenous triglyceride. The efficiency of endogenous triglyceride clearance was determined from the level of serum triglyceride and its turnover rate using the kinetic approach of Reaven et al. [41]. In this technique the transport of serum triglyceride was considered to be similar to a saturable enzyme system.

The results of the investigation performed in the normal subjects and in patients with experimental hypertriglyceridaemia [32] have added further confirmation for the use of this technique in determining endogenous triglyceride clearance. When serum triglyceride concentration (S) was plotted against turnover rate (V) a hyperbolic curve was obtained. At lower levels of triglyceride concentration, removal rates appeared to be proportional to the triglyceride concentration and the relationship was linear. As the maximum turnover rate (V-max) was reached the rate of removal appeared to be independent of triglyceride concentration and the reaction approached zero order kinetics. The relationship between serum triglyceride concentration and turnover in the normal group was constructed and the results from the diabetic patients were examined in this context. Using this approach the removal efficiency was characterised by means of the Michaelis constant, $\mathrm{Km}$, which is the triglyceride concentration at which the triglyceride turnover rate is at half maximal velocity. To calculate the maximum turnover rate and $\mathrm{Km}$ more accurately a linear trans- 
formation of the Michaelis-Menten formulation of [S] against [V] was constructed. As V-max equals the reciprocal of the slope of the regression line obtained, $V$ max was calculated for each individual group of subjects in the studies performed and individual $\mathrm{Km}$ values were calculated from the formula:

$$
\mathrm{Km}=\mathrm{V}-\max -\mathrm{V} \times \frac{[\mathrm{S}]}{\mathrm{V}}
$$

IV. Clearance of exogenous triglyceride. The efficiency of clearance of exogenous triglyceride was determined using the intravenous fat tolerance test described by Boberg et al. [8]. Intralipid $(10 \% \mathrm{~W} / \mathrm{V})$ was given intravenously in a dose of $1 \mathrm{ml} / \mathrm{kg}$ body weight and the fractional turnover rate $\mathrm{K}_{2}$ was calculated from the half-life time of turbidity determined nephelometrically.

V. Post-prandial plasma post-heparin lipolytic activity. Heparin 10 I.U./kg body weight was injected intravenously $90 \mathrm{~min}$ after the intake of an oral glucose load of $50 \mathrm{~g}$. Blood was taken $10 \mathrm{~min}$ later and tho plasma lipolytic activity was measured using the method of Boberg and Carlson [7].

\section{B. Experimental Hypertriglyceridaemia}

Experimental hypertriglyceridaemia was induced in 4 normal volunteers using a continuous infusion of Intralipid ${ }^{\circledR}$. Immediately before the start of the infusion a priming dose of $0.1-0.3 \mathrm{mmol}$ of triglyceride emulsion per $\mathrm{kg}$ body weight was given intravenously within a period of $2 \mathrm{~min}$. The rate of the infusion was then adjusted to deliver between 20 and $30 \mu \mathrm{mol}$ of triglyceride per $\mathrm{kg}$ per hour. This rate was found to be suitable to obtain a constant plasma triglyceride level during the infusion. $3 \mathrm{~h}$ later a glucose infusion at a rate of $0.4-0.6 \mathrm{~g}$ per $\mathrm{kg}$ per hour was commenced in addition to the Intralipid infusion. The combined infusion was continued for another $2 \mathrm{~h}$. Blood samples were taken from a cannula in a vein in the contralateral arm throughout the $5 \mathrm{~h}$ study and the plasma was separated for triglyceride, free fatty acid, glucose and insulin measurements. At the end of the infusions $10 \mathrm{I}$. $\mathrm{U}$. per $\mathrm{kg}$ of heparin were given intravenously and a blood sample was taken $10 \mathrm{~min}$ later for measurement of plasma lipolytic activity. This protocol was repeated with the same subject a week later using intravenous saline infusion instead of Intralipid.

\section{Other Methods}

Oral glucose tolerance tests were performed using $50 \mathrm{~g}$ of glucose. Samples of blood were taken at 0,60 and $120 \mathrm{~min}$ after the glucose load. Measurements of plasma glucose and insulin were performed using the methods of Cramp [12] and Albano et al. [1] respectively. Serum triglyceride levels were measured using a semi-automated fluorimetric method [13]. Standard statistical methods were employed using student's " $t$ " test.

\section{Results}

\section{A. Plasma Free Fatty Acid and Triglyceride Transport Kinetics in Control and Diabetic Subjects}

Table 2 summarises the results of our investigations in the control subjects and in the diabetic patients before and after Phenformin therapy.

I. Free fatty acid turnover rate. The mean plasma free fatty acid concentration and flux in the controls were $680 \pm 172 \mu \mathrm{eq} / \mathrm{l}$ and $274 \pm 45 \mu \mathrm{eq} / \mathrm{min}$ respectively. In both the obese and non-obese diabetic groups (Tables $1 \mathrm{a}$ and $\mathrm{b}$ ) significant elevation of plasma free fatty acid concentration was associated with increased free fatty acid flux into the plasma. There was no significant difference in plasma free fatty acid concentration or flux between the two groups of diabetic patients. The mean plasma free fatty acid concentration was significantly reduced in the diabetic patients during Phenformin therapy. This reduction in free fatty acid concentration was associated with a simultaneous reduction in plasma free fatty acid turnover (Fig. 1).

II. Triglyceride turnover rate. The mean fasting triglyceride concentration in the control group was $1.008 \pm 0.337 \mathrm{mmol} / \mathrm{l}$. In both diabetic groups the mean triglyceride concentration was significantly higher, the greatest increase being in the non-obese patients. Fig. 2 shows the relationship between plasma triglyceride concentration and turnover rates in the control group and diabeties. The mean triglyceride turnover rate in the non-obese diabetics was similar to that of the control subjects so that the individual points of the former lay below the saturation curve of the controls, indicating that in these diabetic patients the hypertriglyceridaemia was due to a defect in triglyceride clearance. The mean triglyceride turnover rate in the obese diabetics was significantly increased so that their individual points lay above the saturation curve of the controls, indicating that in these diabeties hypertriglyceridaemia was in part due to increased triglyceride influx into the plasma. In the entire group of diabetic patients triglyceride turnover rate correlated significantly with the relative body weights of the patients $(\mathrm{r}=0.716, p<0.001)$.

In the non-obese diabetics there was no significant correlation between the plasma free fatty acid turnover and plasma triglyceride turnover rates. A significant correlation was, however, observed between these measurements in the obese diabetics $(r=0.747, p<$ $0.05)$.

With Phenformin therapy the plasma triglyceride concentration was markedly reduced in all the diabetics (Fig. 1 and Table 2). Triglyceride turnover rates were reduced during Phenformin treatment only in the obese diabetics, in whom the turnover values were originally elevated (Fig. 1, Table 2). No significant changes were observed in the non-obese diabetics. When the triglyceride concentration values were 

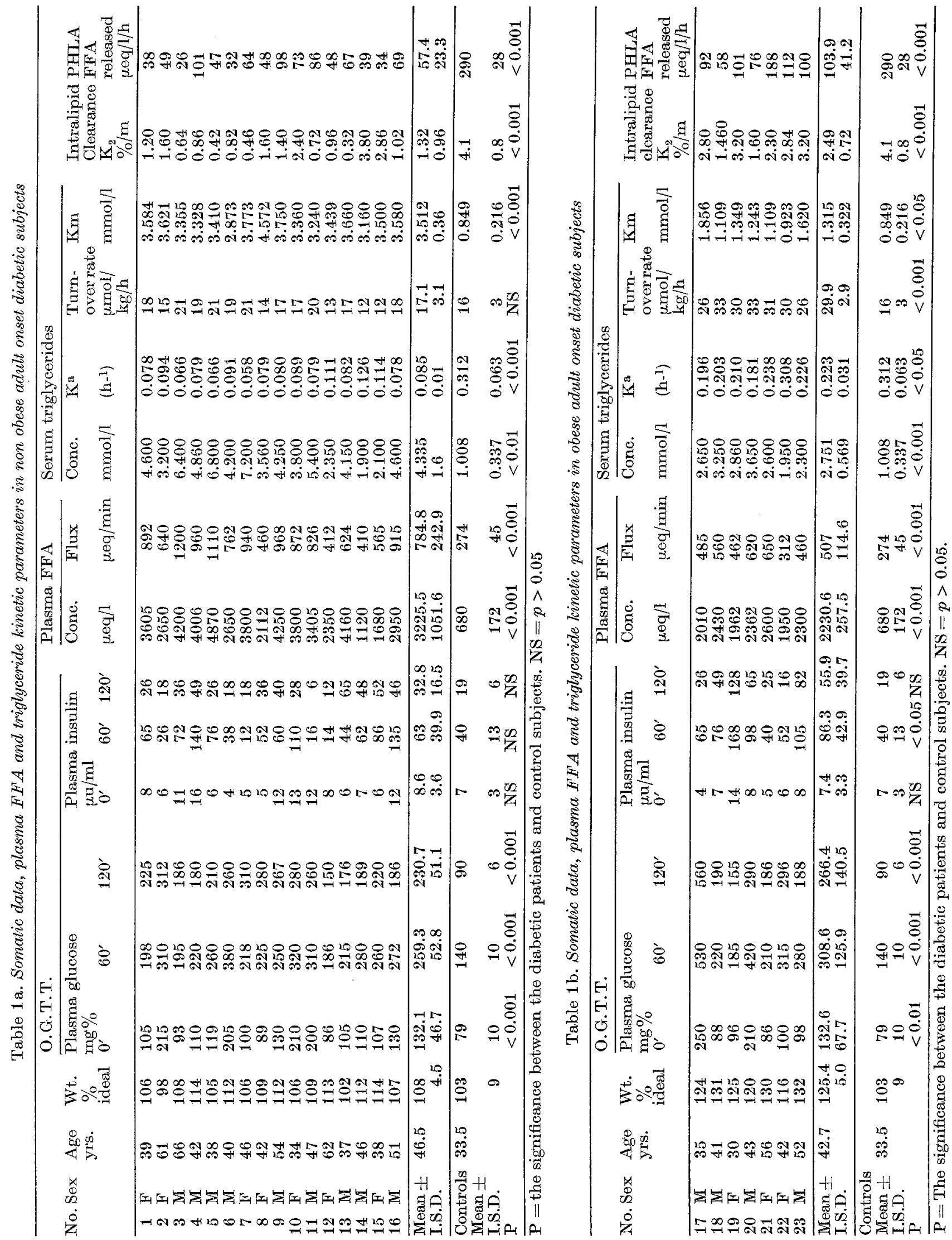
plotted against the triglyceride turnover rates the direction of change indicated that Phenformin treatment restored the turnover kinetics to the normal pattern in the majority of patients studied (Fig. 2). These results suggest that in the obese diabetics the improvement in serum triglyceride concentration was predominantly due to a decrease in plasma triglyceride turnover, whereas in the non-obese diabetics the reduction in serum triglyceride was due to the marked improvement in plasma triglyceride clearance. plasma lipolytic activity was reduced in both groups of patients, the changes being more marked in the nonobese diabetics (Tables $1 \mathrm{a}$ and $\mathrm{b}$ ).

During treatment with Phenformin the $\mathrm{Km}$ value was markedly reduced in all the patients; the values during treatment, with one exception, were within the normal range. These results suggest that Phenformin enhances the clearance of endogenous plasma triglyceride (Fig. 1 and 3). The clearance of exogenous triglyceride, as determined by the fractional transport

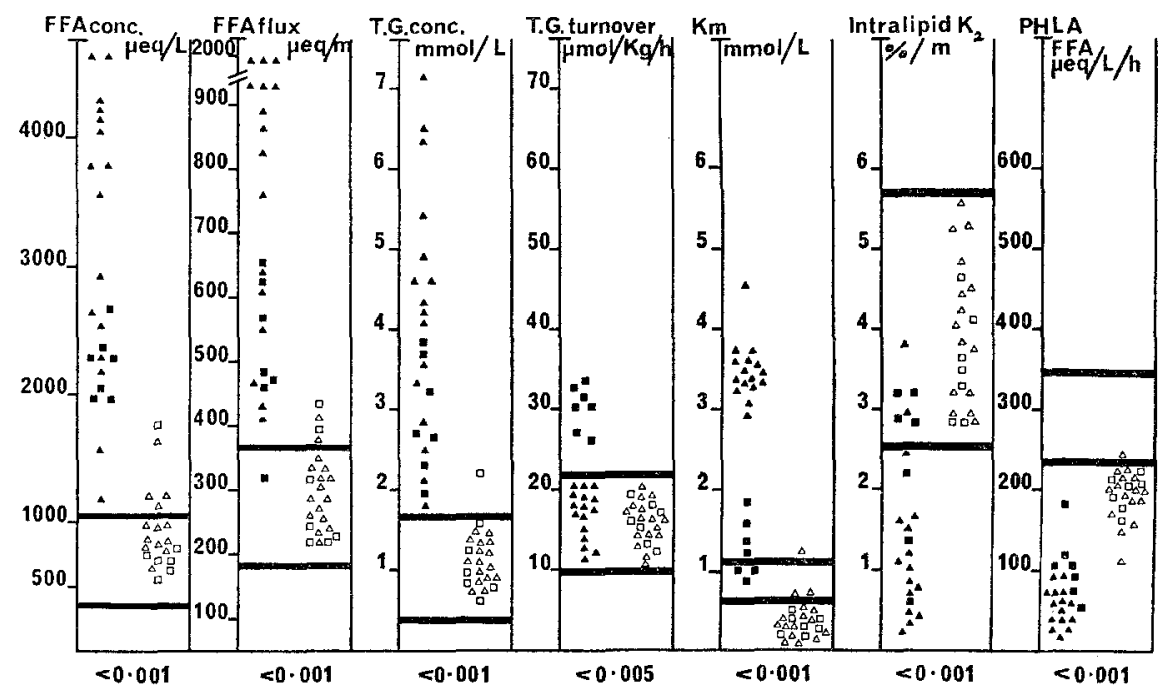

Fig. 1. Individual data of the kinetics of plasma. FFA and triglyceride transport in non-obese and obese maturity onset diabetics. The two horizontal thick lines represent the means of the control group \pm 2 S.D. The triangles $(\Delta \triangle \mathbf{A}$ ) represent the non-obese diabetics, the squares $(\mathbf{R} \square)$ represent the obese diabetics. The closed symbols indicate the results before therapy and the open symbols represent the values during treatment with Phenformin

III. Triglyceride clearance. The plot of [S] against $\frac{[\mathrm{S}]}{V}$ (Fig. 3) showed that the kinetics of triglyceride transport were very different in the non-obese and obese diabetic patients. In the non-obese diabeties the $V$-max was similar to that of the control subjects (about $30 \mu \mathrm{mol} / \mathrm{kg} / \mathrm{h}$ ), while the $\mathrm{V}$-max of the obese diabetics was greatly increased $(44 \mu \mathrm{mol} / \mathrm{kg} / \mathrm{h})$. The $\mathrm{Km}$ of endogenous triglyceride clearance in the nonobese diabetics was significantly higher than that of the control subjects indicating that clearance of endogenous plasma triglyceride was severely impaired and that, in the presence of a normal triglyceride turnover rate, this accounted for the severe degree of hypertriglyceridaemia observed in these patients. On the other hand, the obese diabetics had only slight impairment of clearance of endogenous plasma triglyceride, as in this group elevation of the $K m$ was small, thus indicating that enhanced triglyceride influx into the plasma was the predominant cause of their hypertriglycerid. aemia.

Clearance of exogenous triglyceride was impaired in both groups of diabetic patients, as shown by low intralipid $K_{2}$ values (Table $1 \mathrm{a}$ and b). Post heparin

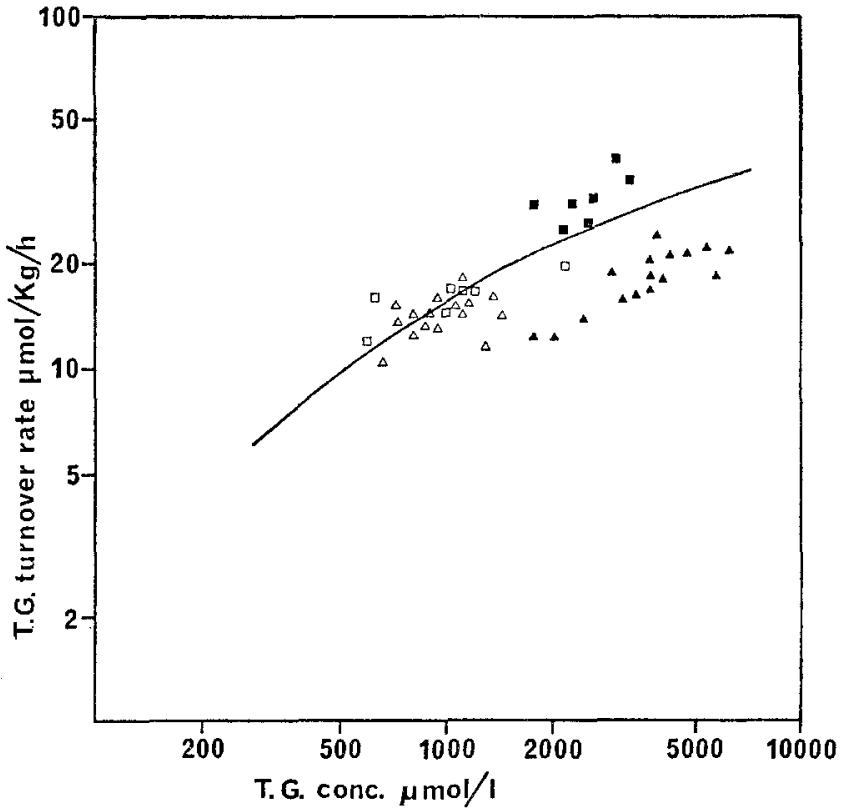

Fig. 2. Relationship between serum triglyceride concentration and turnover rate in controls and maturity onset diabetics before and after Phenformin treatment. The curved line represents the saturation curve for the control group. Symbols as in Fig. 1 
rate of Intralipid, was also improved during Phenformin therapy (Fig. 1 and Table 2). The improvement in plasma triglyceride clearance induced by Phenformin was also associated with enhanced release of lipolytic activity into the plasma in response to heparin (Fig. 1 and Table 2).

\section{B. Glucose Insulin Relationships in the Controls and Diabetics, and the Effects of Experimental Hypertri- glyceridaemia}

In both groups of diabetics plasma glucose levels fasting and during the oral glucose tolerance test were similar, and greatly exceeded the values observed in the control subjects (Tables $1 \mathrm{a}$ and $\mathrm{b}$ ). Fasting plasma insulin levels were similar to those observed in the controls. Plasma insulin responses following oral glucose were not statistically different in the diabetic groups, though the levels in the obese diabetics tended to be higher than those in the non-obese. In the former patients the plasma insulin levels at 60 and $120 \mathrm{~min}$ were significantly higher $(p<0.01, p<0.05$ respectively) than those in the control subjects. In both diabetic groups there was no correlation between plasma glucose or insulin and triglyceride concentration and turnover rate.

During treatment with Phenformin there was a marked improvement in glucose tolerance and the mean values of fasting, 60 and $120 \mathrm{~min}$ plasma glucose and insulin fell within the range of the control subjects (Table 2). Fig. 4 shows the relationship between the insulin response and glucose levels at $60 \mathrm{~min}$ in the control subjects and in the diabetics, before and during Phenformin therapy. Before treatment, though the insulin responses in most of the diabetics were within or above the range observed in the controls, the plasma glucose levels were markedly elevated. During Phenformin therapy, the plasma insulin responses and glucose levels were reduced, so that the majority of individual points fell within the range observed in the control subjects.

In the healthy volunteers plasma glucose and insulin levels were not altered by the infusion of Intralipid, during which time plasma free fatty acid and triglyceride concentrations were elevated. During the glucose infusions, in the latter part of the experiment the resultant plasma glucose profiles were identical with and without the simultaneous infusion of Intralipid. However, the plasma insulin responses to glucose were significantly higher when Intralipid was being infused than during the saline infusion (Fig. 5, Table 3). Post-heparin, plasma lipolytic activity measured at the end of the experiments was significantly reduced by the Intralipid infusion, but not by saline.

\section{Discussion}

Despite several studies of the inter-relationship between diabetes and hyperlipidaemia it is difficult to

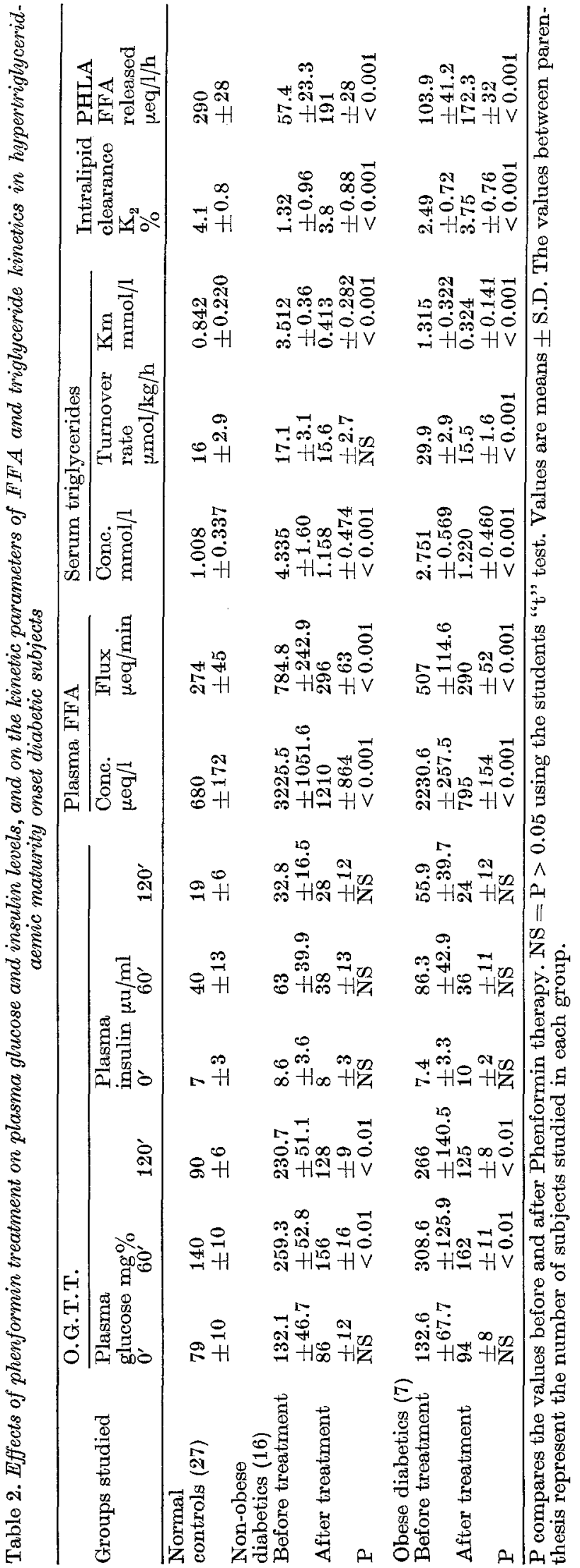


draw conclusions concerning the plasma lipid pattern in patients with diabetes. The plasma levels of triglyceride and cholesterol may vary from day to day and are dependent on the dietary habit and degree of obesity. Furthermore, the type of diabetes and the
On the other hand, Östman [39] did not find increased triglyceride levels in untreated diabetics, compared to a non-diabetic group matched for age and obesity.

The mechanism of hypertriglyceridaemia associated with juvenile diabetes has been thoroughly investigated

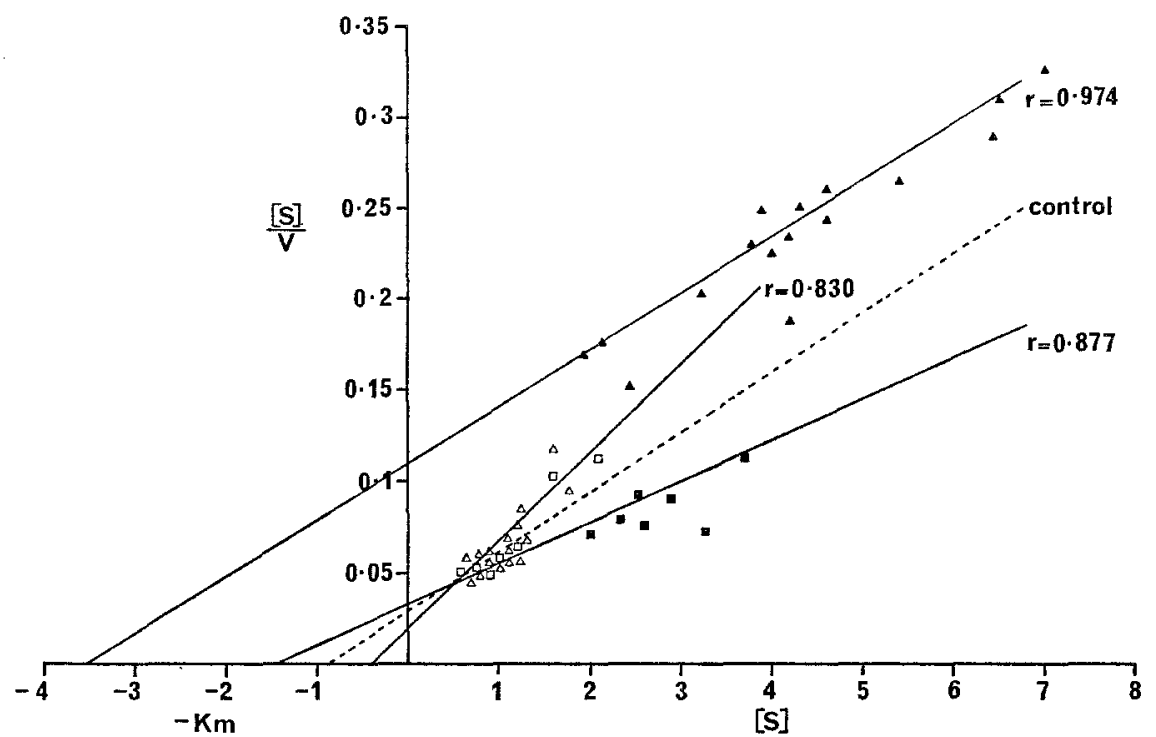

Fig. 3. The plot $[\mathrm{S}]$ against $\frac{[\mathrm{S}]}{\mathrm{V}}$ in the control group (-.) and in obese and non-obese maturity onset diabetics before and after Phenformin therapy. Symbols as in Fig. 1. ( $\mathrm{S}=$ serum triglyceride concentration in mmoles $/ 1$. $V=$ serum triglyceride turnover rate in umoles $/ \mathrm{kg} / \mathrm{h}$ )

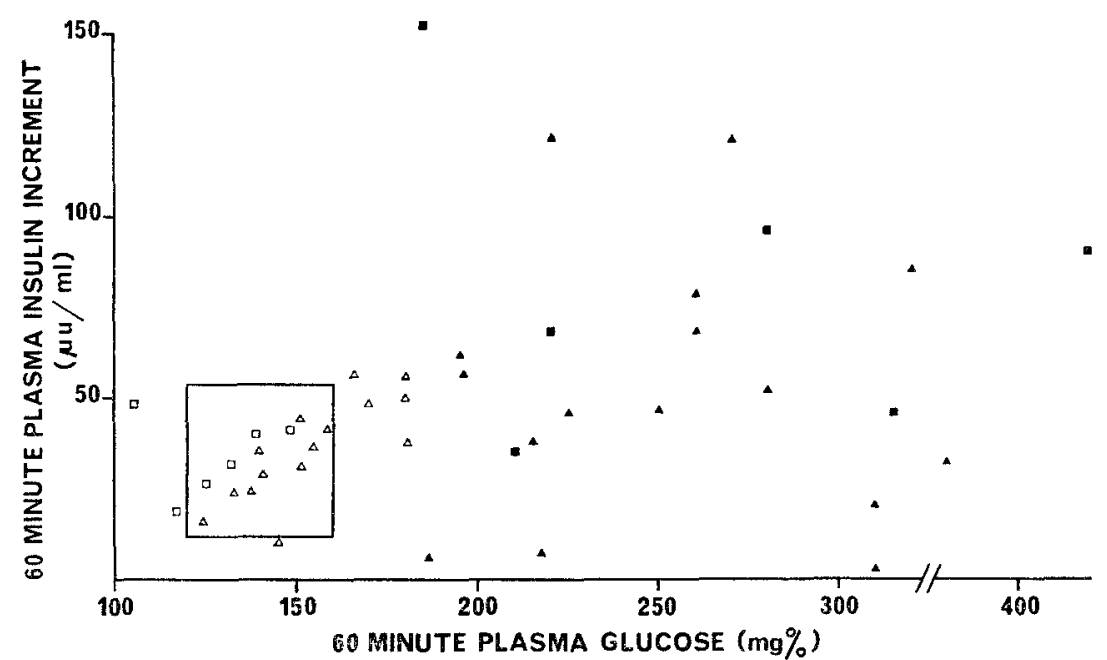

Fig. 4. The relationship between the $60 \mathrm{~min}$ plasma glucose values and the insulin increment above the fasting values in the control subjects and diabetic patients before and after Phenformin administration. The rectangle represents the mean values \pm 2 S.D. in the control subjects. Symbols as in Fig. 1

degree of diabetic control may also influence the plasma triglyceride levels. Khachadurian and Uthman [29] and Avogaro et al. [3] reported a significant elevation of serum triglycerides in a large, heterogeneous group of diabetics, as compared to non-diabetic subjects. Hayes [27] studied 106 untreated diabetics and found an incidence of $68 \%$ of hyperlipidaemia in these patients. in man and experimental animals. In man, deficiency of lipoprotein lipase and impaired clearance of triglyceride has been reported $[4,24]$.

The contribution of hepatic production of triglycerides in juvenile diabetes remains unclear. In alloxan diabetic rats the in vitro synthesis of hepatic triglycerides was markedly increased [11]. However, 
in diabetic dogs the incorporation of plasma free fatty acid into plasma VLDL triglycerides was decreased [5]. In human juvenile diabetes early reports suggested that the hepatic production of triglyceride was normal $[14,42]$. However, a recent investigation [38] has shown that hepatic triglyceride production was markedly raised and accounted for the hypertriglyceridaemia associated with this type of diabetes.

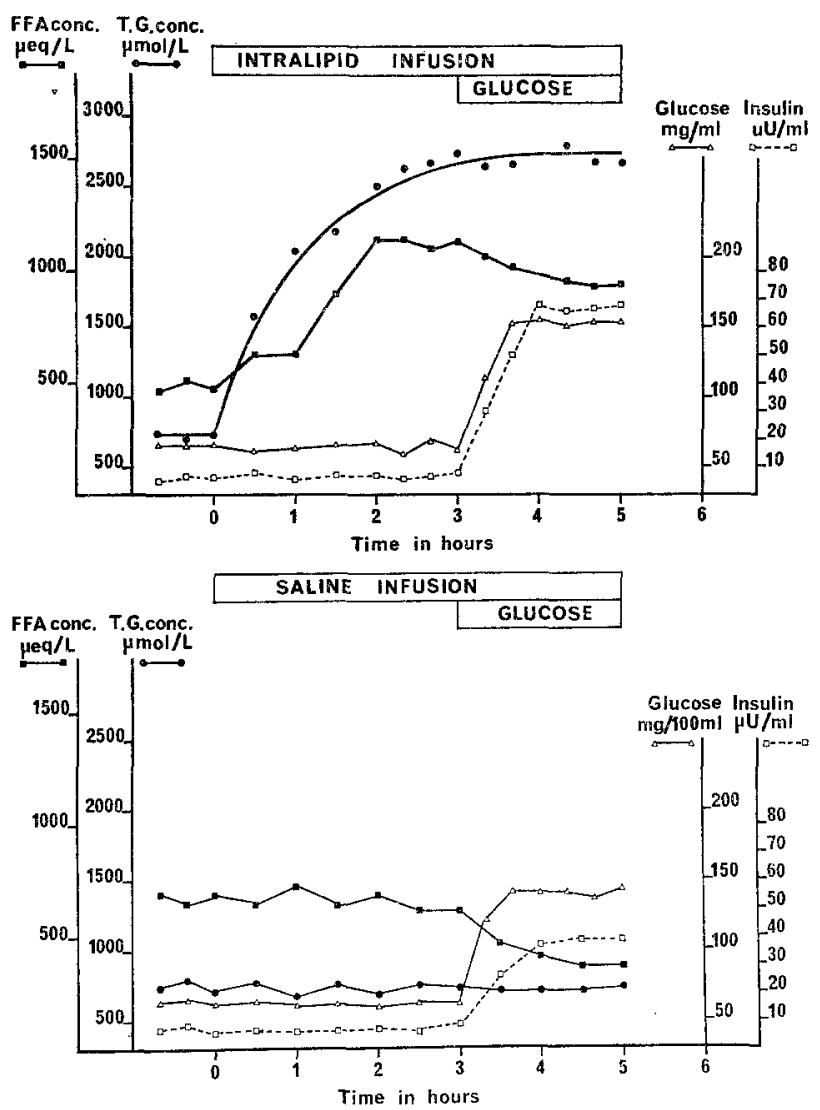

Fig. 5. Effect of experimental hypertriglyceridaemia induced by Intralipid infusion on plasma FFA and insulin response to glucose infusion in a normal subject. The lower graph shows the same results when saline was infused instead of Intralipid.

The dynamics of triglyceride transport in maturity onset diabetics have not been extensively studied and therefore it has not been possible to determine the relative importance of any one factor in the pathogenesis of the hypertriglyceridaemia associated with this disease. Elkeles et al. [17], in a preliminary survey, reported elevated triglyceride levels in $25 \%$ of maturity onset diabetics. It was further observed by the same authors that patients with moderate or high insulin response to oral glucose had higher triglyceride levels than those with poor insulin response. Farquhar et al. [19] studied the effects of high carbohydrate feeding on serum triglycerides and concluded that patients with high insulin responses were those who developed. hypertriglyceridaemia. These results suggested that the hypertriglyceridaemia in this situation might be secondary to the high levels of circulating insulin stimulat. ing hepatic triglyceride synthesis. In the present study an attempt has been made to evaluate the various parameters of free fatty acid and triglyceride transport kinetics in a group of 23 maturity onset hypertriglyceridaemic diabetics.

In the non-obese diabetic patients elevated plasma triglyceride concentrations were associated with normal triglyceride turnover rates. These results suggested that decreased efficiency of the triglyceride clearing mechanisms was the basis of the hypertriglyceridaemia observed in these subjects. This conclusion was also substantiated by the finding of a marked increase in the apparent $\mathrm{Km}$ of endogenous triglyceride clearance. Furthermore, the individual plasma triglyceride concentrations were not related to their production rate, which indicates that the degree of increase in triglyceride levels was determined by the deficiency of the removal system in this group of diabetics. The impairment of fractional transport rate of exogenous triglyceride in the form of Intralipid, added further evidence for this hypothesis.

The obese diabetics, on the other hand, showed higher values of triglyceride turnover rate as compared to the control group, suggesting that elevated triglyceride secretion into the plasma was in part responsible for their state of hypertriglyceridaemia. However, some degree of impairment of both endogenous and exogenous triglyceride clearance was observed in these patients. No definite conclusion, however, can be drawn from this study, since the number of patients studied in this group was small and our control group did not contain obese subjects. It is of importance to recognise that obesity is associated with increased plasma triglyceride turnover [34]; in fact there was a significant correlation between the degree of obesity and triglyceride turnover in this limited group of diabetics.

In the present study the plasma free fatty acid turnover in the diabetics was markedly accelerated, suggesting that fatty acid mobilisation was increased. Previous reports [39] have shown that adiposetissue from diabetics exhibits higher rates of lipolysis than nondiabetic tissue, when incubated in vitro. The association of enhanced lipolysis and impaired triglyceride clearance observed in these diabetic patients is not surprising since the enzymes, triglyceride lipase and lipoprotein lipase, regulating these two processes are known to change in a reciprocal direction in response to a number of physiological and pathological conditions. Thus Shafrir and Biale [47] have observed a decrease in adipose tissue lipoprotein lipase during stimulation of lipolysis, and Nikkilä and Pykälistö [35] found a negative correlation between the rates of mobilisation of fatty acids and the lipoprotein lipase activity in rat adipose tissue. In the present study we have also observed impaired release of lipoprotein lipase into the plasma, in response to heparin, associated with en- 
hanced lipolysis. The activity of the lipoprotein lipase enzyme determines the overall disappearance of plasma triglyceride [44].

Wing and Robinson [51] reported evidence suggesting that the triglyceride lipase and lipoprotein lipase enzymes are controlled by a common mediator, $3^{\prime}-5^{\prime}$ c-AMP. Elevation in tissue levels of this compound activates triglyceride lipase and inhibits lipoprotein lipase, resulting in enhanced lipolysis and impaired triglyceride clearance. Nikkilä and Pylkälistö [35], on the other hand, suggested that the changes in lipoprotein lipase activity in this situation were secondary to the increased intracellular concentration of fatty acids, associated with enhanced lipolysis, which might exert regulatory control over the synthesis of the lipoprotein lipase. be secondary to inhibition of lipolysis, resulting in reduced supply of fatty acids for plasma triglyceride synthesis. In support of this is the observation that reduction of plasma FFA by nicotinic acid is associated with lowering of the serum triglyceride levels in patients with maturity onset diabetes [3].

It is difficult to reconcile the association of enhanced lipolysis and the normal or moderately elevated insulin levels observed in the diabetic patients, since insulin exerts marked anti-lipolytic effects in vivo and in vitro $[16,50,40]$. It is possible, however, that the insulin sensitivity of the fat cells of these patients is reduced, resulting in less inhibition of fatty acid release. The observed insulin levels could therefore be secondary to the high concentration of circulating fatty acids and triglyceride substances, which have been reported to

Table 3. Effects of experimental hypertriglyceridaemia on plasma triglycerides, $F . F . A$. and insulin response to glucose infusion

\begin{tabular}{|c|c|c|c|c|c|c|c|c|}
\hline \multirow[b]{3}{*}{$\begin{array}{l}\text { Exp. } \\
\text { No. }\end{array}$} & \multirow[b]{3}{*}{ Type of study } & \multicolumn{6}{|c|}{ Steady state concentrations } & \multirow{3}{*}{ 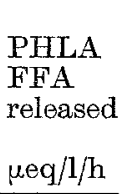 } \\
\hline & & \multicolumn{4}{|c|}{ Before glucose infusion } & \multicolumn{2}{|c|}{ During glucose infusion } & \\
\hline & & $\begin{array}{l}\text { Triglyc. } \\
\text { cone. } \\
\text { mmol/l }\end{array}$ & $\begin{array}{l}\text { FFA } \\
\text { cone. } \\
\mu e q / 1\end{array}$ & $\begin{array}{l}\text { Glucose } \\
\text { conc. } \\
\text { mg\% } \%\end{array}$ & $\begin{array}{l}\text { Insulin } \\
\text { conc. } \\
\mu u / m l \\
\end{array}$ & $\begin{array}{l}\text { Glucose } \\
\text { conc. } \\
\mathrm{mg} \%\end{array}$ & $\begin{array}{l}\text { Insulin } \\
\text { cone. } \\
\mu \mathrm{u} / \mathrm{ml}\end{array}$ & \\
\hline 1. & $\begin{array}{l}\text { Control } \\
\text { Intralipid }\end{array}$ & $\begin{array}{l}0.720 \\
2.650\end{array}$ & $\begin{array}{l}620 \\
908\end{array}$ & $\begin{array}{l}72 \\
68\end{array}$ & $\begin{array}{l}7 \\
9\end{array}$ & $\begin{array}{l}145 \\
156\end{array}$ & $\begin{array}{l}38 \\
68\end{array}$ & $\begin{array}{l}285 \\
190\end{array}$ \\
\hline 2. & $\begin{array}{l}\text { Control } \\
\text { Intralipid }\end{array}$ & $\begin{array}{l}1.210 \\
3.860\end{array}$ & $\begin{array}{r}910 \\
1260\end{array}$ & $\begin{array}{r}96 \\
110\end{array}$ & $\begin{array}{r}11 \\
8\end{array}$ & $\begin{array}{l}140 \\
149\end{array}$ & $\begin{array}{l}42 \\
82\end{array}$ & $\begin{array}{l}320 \\
118\end{array}$ \\
\hline 3. & $\begin{array}{l}\text { Control } \\
\text { Intralipid }\end{array}$ & $\begin{array}{l}1.016 \\
4.860\end{array}$ & $\begin{array}{r}725 \\
1286\end{array}$ & $\begin{array}{l}66 \\
74\end{array}$ & $\begin{array}{l}4 \\
3\end{array}$ & $\begin{array}{l}162 \\
148\end{array}$ & $\begin{array}{r}28 \\
113\end{array}$ & $\begin{array}{l}226 \\
174\end{array}$ \\
\hline 4. & $\begin{array}{l}\text { Control } \\
\text { Intralipid }\end{array}$ & $\begin{array}{l}0.650 \\
6.800\end{array}$ & $\begin{array}{r}680 \\
1220\end{array}$ & $\begin{array}{l}96 \\
82\end{array}$ & $\begin{array}{l}8 \\
6\end{array}$ & $\begin{array}{l}138 \\
146\end{array}$ & $\begin{array}{r}29 \\
126\end{array}$ & $\begin{array}{l}318 \\
126\end{array}$ \\
\hline$P$ & & $<0.001$ & $<0.01$ & NS & NS & NS & $<0.001$ & $<0.001$ \\
\hline
\end{tabular}

$P$ compares the paired data from the infusion studies with the control values. Levels of significance were determined using" the students " $t$ " test.

NS $=P>0.05$.

It is therefore possible that, in the present study, the impairment in plasma triglyceride clearance observed in the diabetic patients was secondary to enhanced lipolysis. The changes observed during Phenformin therapy add further support to this hypothesis. Phenformin has been shown to exert anti-lipolytic effects in rat adipose tissue $[6,18]$. Similar effects have also been observed in human adipocytes [Kissebah unpublished]. The results of the presentinvestigation also show that this drug lowers the plasma FFA concentration and flux in diabetic subjects. The reduction in fatty acid mobilisation was associated with marked improvement in plasma triglyceride clearance. Thus the $\mathrm{Km}$ of endogenous triglyceride clearance and the $K_{2}$ of Intralipid removal were markedly improved during Phenformin therapy. The post heparin plasma lipolytic activity was also increased during treatment. In the obese diabetics, however, the reduction in serum triglyceride concentration was, at least in part, due to inhibition of triglyceride release into the plasma. This effect might also increase insulin secretion both in vivo and in vitro [23, $36,33]$. In the present study normal subjects were infused with Intralipid and the plasma insulin response to a glucose infusion was determined. It was observed that the elevation in plasma free fatty acid and triglycerides during the Intralipid infusion augmented the insulin response of these subjects without alteration in the plasma glucose profile. Furthermore, in the diabetic patients the reduction in plasma FFA flux during Phenformin therapy was associated with a decrease in the plasma insulin response following a glucose load.

It is also possible that the hyperglycaemia observed in the diabetic patients was in part due to the enhanced lipolysis, since FFA compete with glucose for oxidation by skeletal muscle [40]. Elevations of plasma FFA by infusion of fat emulsions $[45,46,22]$ resulted in impaired glucose utilisation. In the present study the reduction in plasma FFA flux induced by Phenformin was associated with improvement in glucose tolerance. 
These results, however, do not exclude the possibility of direct effects by Phenformin upon the glucose insulin relationships.

As regards the nature of the initial lesion responsible for the insulin insensitivity observed in these patients, our previous studies in human adipose tissue biopsies suggested that the responsiveness of the glycerides were labelled using two different techniques. In the first technique the plasma VLDL triglycerides were labelled endogenously during a continuous infusion of ${ }^{14} \mathrm{C}$ palmitate, described under the method section in this paper. In the second technique plasma VLDL triglycerides were labelled endogenously with ${ }^{14} \mathrm{C}$ palmitate and withdrawn to be re-injected into the

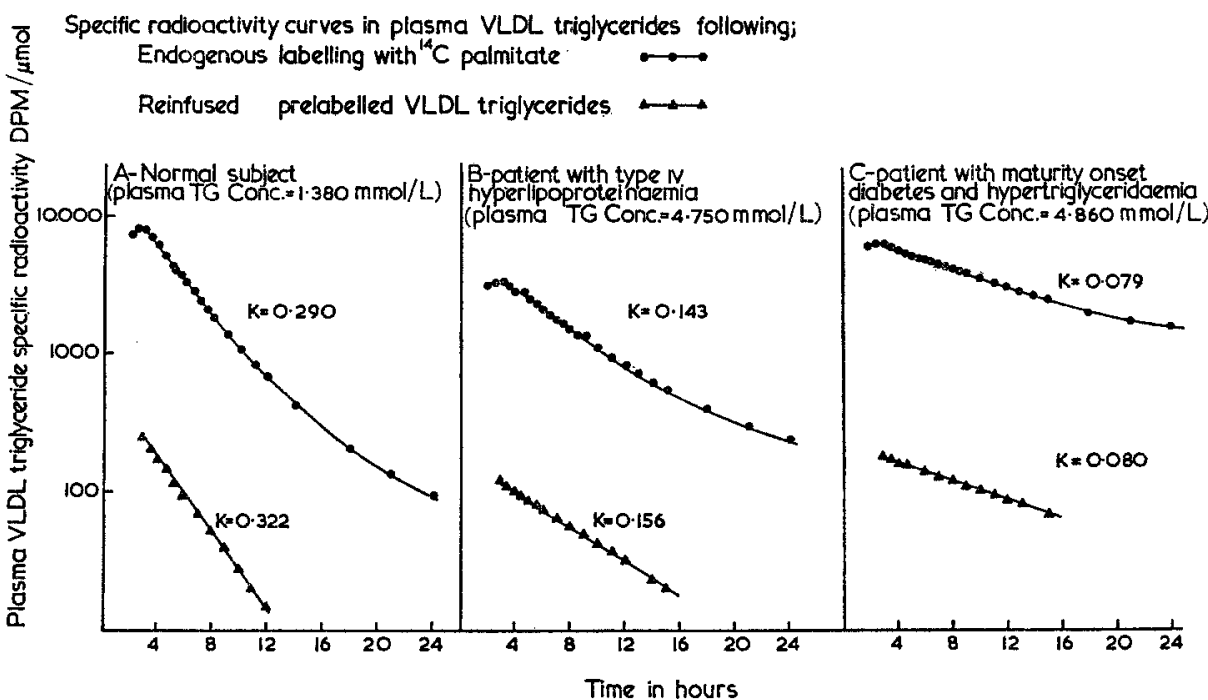

Fig. 6 (Appendix). Plasma VLDL triglyceride specific radioactivity following endogenous labelling with ${ }^{14} \mathrm{C}$ palmitate, and re-injected prelabelled VLDL triglyceride. $\left(\mathrm{K}=\frac{0.693}{\mathrm{t} 1 / 2}\right)$

Table 4. Mean (with ranges) measurements of plasma VLDL triglyceride transport in man obtained using two techniques (see text)

\begin{tabular}{|c|c|c|c|c|}
\hline \multirow{3}{*}{ Group studied } & \multirow{3}{*}{$\begin{array}{l}\text { Plasma triglyceride } \\
\text { Conc. mmol/1 }\end{array}$} & \multicolumn{3}{|c|}{ Plasma VLDL triglyceride turnover rates } \\
\hline & & \multirow{2}{*}{$\begin{array}{l}\text { Endogenous labelling } \\
\text { with } 14 \mathrm{C} \text { palmitate } \\
\mu \text { mole } / \mathrm{kg} / \mathrm{h}\end{array}$} & \multicolumn{2}{|c|}{$\begin{array}{l}\text { Reinfusion of } 14 \mathrm{C} \text { prelabelled VLDL } \\
\text { triglyceride }\end{array}$} \\
\hline & & & $\begin{array}{l}\text { Total transport } \\
\mu \mathrm{mole} / \mathrm{kg} / \mathrm{h}\end{array}$ & $\begin{array}{l}\% \text { of total triglyceride } \\
\text { transport converted to } \\
\text { plasma FFA }\end{array}$ \\
\hline $\begin{array}{l}\text { Normal subjects } \\
\mathbf{N}=8\end{array}$ & $\begin{array}{l}0.891 \\
(0.500-1.380)\end{array}$ & $\begin{array}{l}15.4 \\
(11-20)\end{array}$ & $\begin{array}{l}17.1 \\
(14-22)\end{array}$ & $\begin{array}{l}16.9 \\
(12.7-26)\end{array}$ \\
\hline $\begin{array}{l}\text { Type IV hypertri- } \\
\text { glyceridaemic patients } \\
\mathrm{N}=4\end{array}$ & $\begin{array}{l}3.012 \\
(2.10-4.75)\end{array}$ & $\begin{array}{l}30 \\
(26-34)\end{array}$ & $\begin{array}{l}33.5 \\
(26-36)\end{array}$ & $\begin{array}{l}15.3 \\
(10-18.5)\end{array}$ \\
\hline $\begin{array}{l}\text { Diabetic patients } \\
\mathbf{N}=\mathbf{4}\end{array}$ & $\begin{array}{l}2.862 \\
(2.10-3.80)\end{array}$ & $\begin{array}{l}14.3 \\
(12-17)\end{array}$ & $\begin{array}{l}15 \\
(12-18)\end{array}$ & $\begin{array}{l}18.1 \\
(14.4-21.3)\end{array}$ \\
\hline
\end{tabular}

$\mathrm{N}=$ Number of subjects studied

enzymes regulating the c-AMP levels in this tissue was diminished [30]. The resultant, elevated intracellular c-AMP levels stimulate the release of fatty acids in spite of the normal levels of circulating insulin. How much of this derangement is due to a primary cellular abnormality or due to humoral factors remains to be identified.

\section{Appendix}

Fig. 6 shows the disappearance curves of VLDL triglycerides in three subjects in whom the plasma tri- same patient two weeks later. These curves are part of a study performed in 8 normal subjects and 8 patients with hypertriglyceridaemia to assess the validity of the techniques employed to measure plasma triglyceride turnover [32].

The parallelism between the curves (Fig. 6) and the close agreement between the turnover values determined by the two techniques (Table 4) indicated that direct recycling of fatty acids from plasma triglycerides into the plasma FFA pool was minimal and did not affect the triglyceride radioactivity curves. In 
order to quantitate this pathway more precisely, the plasma FFA radioactivity curves were analysed after injection of ${ }^{14} \mathrm{C}$ prelabelled VLDL triglycerides and ${ }^{3} \mathrm{H}$ labelled FFA [48]. The results shown in Table 4 indicate that less than $20 \%$ of the total plasma triglyceride transport can be converted immediately to plasma FFA. When one considers the fact that the plasma FFA flux is about $4-5$ fold higher than that of triglycerides, this recycling can account for less than $5 \%$ of the plasma FFA flux. As evident from this study, as well as others [26], less than $20 \%$ of the plasma FFA flux is converted to triglycerides. It becomes apparent, therefore, that recycling can produce negligible effects on the turnover measurement both in normal and hypertriglyceridaemic subjects.

Using the technique described the rate constant for plasma triglyceride transport in normal subjects ranged between $0.211-0.492$. These values are comparable to those of Friedberg et al. [21] who used an integration method and those reported by Reaven et al. [41], and Niklkilä and Kekki [37] who used the ${ }^{3} \mathrm{H}$ glycerol labelling technique. These results encouraged us to use the endogenous labelling technique for its simplicity and convenience.

\section{References}

1. Albano, J.D., Ekins, R.P., Maritz, G., Turner, R.C.: A sensitive precise radio-immuno assay of serum insulin relying on charcoal separation of bound and free hormone moieties. Acta endocr. (Kbh.) 70, 487-509 (1972)

2. Albrink, M.J., Lavietes, P.H., Man, E.B.: Vascular disease and serum lipids in diabetes mellitus; observations over thirty years. Ann. intern. Med. 58, 305-323 (1963)

3. Avogaro, P., Capri, C., Gazzolato, G., Pais, M.: Lipid disorders in diabetes mellitus. Acta diabet. lat. 9, $540-561$ (1972)

4. Bagdade, J.D., Porte, D., Jr., Bierman, E.L.: Acute insulin withdrawal and the regulation of plasma triglyceride removal in diabetic subjects. Diabetes 17, $127-132$ (1968)

5. Basso, L.V., Havel, R.J.: Hepatic metabolism of free fatty acids in normal and diabetic dogs. J. clin. Invest. 49, 537-547 (1970)

6. Brown, J.D., Stone, D.B., Steele, A.A.: Mechanism of action of antilipolytic agents: comparison of the effects of insulin, tolbutamide and phenformin on lipolysis induced by dibutyryl cyclic AMP plus theophylline. Metabolism 18, 926-929 (1969)

7. Boberg, J., Carlson, L.A.: Determination of heparin induced lipoprotein lipase activity in human plasma. Clin. chim. Acta 10, 420-427 (1964)

8. Boberg, J., Carlson, L.A., Hallberg, D.: Application of new intravenous fat tolerance test in the study of hypertriglyceridaemia in man. J. Atheroscler. Res. 9, 159-169(1969)

9. Carlson, L.A.: Serum lipids in men with myocardial infarction. Acta med. scand. 167, $399-413$ (1960)

10. Carlson, L. A., Böttiger, L. E.: Ischaemic heart disease in relation to fasting values of plasma triglycerides and cholesterol. Lancet 1972 I, 865-868

11. Corder, C.N., Kalkhoff, R.K.: Hepatic lipid metabolism in alloxan diabetic rats. J. Lab. clin. Med. 73, $551-563(1969)$
12. Cramp, D.G.: New automated method for measuring glucose by glucose oxidase. J. clin. Path. 20,910-912 (1967)

13. Cramp, D.G., Robertson, G.R.: The fluorimetric assay of triglyceride by a semi-automated method. Analyt. Biochem. 25, 246-251 (1968)

14. Csorba, T.R., Matsuda, I., Kalant, N.: Effects of insulin and diabetes on flux rates of plasma glucose and free fatty acids. Metabolism 15, 262-270 (1966)

15. Davidson, P.C., Albrink, M.J.: Abnormal plasma insulin response with high plasma triglycerides independent of clinical diabetes or obesity (Abs.) J. clin. Invest. 45, 1000 (1966)

16. Dole, V.P.: A relation between non-esterified fatty acids in plasma and the metabolism of glucose. J. clin. Invest. 35, 150-154 (1956)

17. Elkeles, R.S., Lowy, C., Wyllie, A.D.H., Young, J.L., Fraser, T.R.: Serum insulin, glucose and lipid levels among mild diabetics in relation to incidence of vascular complications. Lancet 1971 I, $880-883$

18. Elkeles, R.S.: The direct effect of oral hypoglycaemic agents on glucose metabolism by adipose tissue. Horm. Metab. Res. 4, 178-182 (1972)

19. Farquhar, J.W., Frank, A., Gross, R.C., Reaven, G. M.: Glucose, insulin and triglyceride responses to high and low carbohydrate diets in man. J. clin. Invest. 45, $1648-1656(1966)$

20. Ford, S., Jr., Bozian, R.C., Knowles, H.C., Jr.: Interactions of obesity and glucose and insulin levels in hypertriglyceridaemia. Amer. J. clin. Nutr. 21, $904-$ 910 (1968)

21. Friedberg, S.J., Klein, R.F., Trout, D.L., Bogdonoff, M.D., Estes, E.H.: The incorporation of plasma free fatty acids into plasma triglycerides in man. J. clin. Invest. 40, 1846-1855 (1961)

22. Gómez, F., Jéquier, E., Chabot, V., Büber, V., Felber, J.-P.: Carbohydrate and lipid oxidation in normal human subjects: its influence on glucose tolerance and insulin response to glucose. Metabolism 21, 381-391 (1972)

23. Greenough, W.B., III., Crespin, S.R., Steinberg, D.: Hypoglycaemia and hyperinsulinaemia in responso to raised free fatty acid levels. Lancet 1967 II, 13341336

24. Gries, F.A., Oberdisse, K.: Fettstoffwechselstörungen und Diabetes Mellitus. Dtsch. med. Wschr. 95, $727-734(1970)$

25. Havel, R.J., Carlson, L.A.: Serum lipoproteins, cholesterol and triglycerides in coronary heart disease. Metabolism 11, 195 - 197 (1962)

26. Havel, R.J., Kane, J.P., Balasse, E.O., Segal, N., Basso, L.V.: Splanchnic metabolism of free fatty acids and production of triglycerides of very low density lipoproteins in normotriglyceridaemic and hypertriglyceridaemic humans. J. elin. Invest. 49, $2017-2035(1970)$

27. Hayes, T.M.: Plasma lipoproteins in adult diabetes. Clin. Endoer. 1, 247-251 (1972)

28. Keen, H., Jarrett, R.J.: The effect of carbohydrate tolerance on plasma lipids and atherosclerosis in man. In proceedings of the Second International Symposium on atherosclerosis, pp. 435 (Ed. Jones, R.J.). BerlinHeidelber-New York: Springer-Verlag 1970

29. Khachadurian, A.K., Uthman, S.M.: Plasma lipids in diabetes mellitus. J. méd. liban. 24, 105-115 (1971)

30. Kissebah, A.H., Fraser, T.R.: The in vitro ${ }^{14} \mathrm{C}$-cyclic AMP production by normal human adipose tissue in response to some hormones and in uncontrolled and controlled diabetic adipose tissue. Horm. Metab. Res. 4, 72-77 (1972)

31. Kissebah, A.H., Harrigan, P., Wynn, V.: Mechanism of hypertriglyceridaemia associated with contra- 
ceptive steroids. Horm. Metab. Res. 5, 184-190 (1973)

32. Kissebah, A.H., Adams, P.W., Wynn, V.: Measurement of plasma free fatty acid and triglyceride kinetics in man. In preparation (1973)

33. Malaisse, W.J., Malaisse-Lagae, F.: Stimulation of insulin secretion by non-carbohydrate metabolites. $J$. Lab. clin. Med. 72, 438-448 (1968)

34. Nestel, P.J., Whyte, H.M.: Plasma free fatty acid and triglyceride turnover in obesity. Metabolism 17, $1122-1128$ (1968)

35. Nikkilä, E.A., Pykälistö, O.: Induction of adipose tissue lipoprotein lipase by nicotinic acid. Biochem. Biophys. Aota 152, 421-423 (1968)

36. Nikkilä, E.A., Taskinen, M.R.: Hypertriglyceridaemia and insulin secretion, a complex casual relationship. In: Atherosclerosis, Procs. Second Intern. Symp., p. 220 (Ed. Jones, R.J.). Berlin-HeidelbergNew York: Springer-Verlag 1970

37. Nikkilä, E.A., Kekki, M.: Polymorphism of plasma triglyceride kinetics in normal human adult subjects. Acta. med. scand. 190, 49-59 (1971)

38. Nikkilä, E.A., Kekki, M.: Plasma triglyceride transport kinetics in diabetes mellitus. Metabolism 22, 122 (1973)

39. Östman, J.: Studies in vitro on fatty acid metabolism of human subcutaneous adipose tissue in diabetes mellitus. Acta. med. scand. 177, 639-655 (1965)

40. Randle, P.J., Garland,P.B., Hales, C.N., Newsholme, E.A.: The glucose fatty acid cycle. Its role in insulin sensitivity and the metabolic disturbances of diabetes mellitus. Lancet $1963 \mathrm{I}, 785-789$

41. Reaven, G.M., Hill, D.B., Gross, R.C., Farquhar, J. W.: Kinetics of triglyceride turnover of very low density lipoproteins of human plasma. J. clin. Invest. 44, $1826-1833$ (1965)

42. Sailer, S., Sandhofer, F., Braunsteiner, H.: Beziehungen zwischen Blutzuckerspiegel, Umsatzrate der freien Fettsäuren und Fettsäureeinbau in Plasmatriglyceride bei Diabetikern. Klin. Wschr. 45, 86-91 (1967)

43. Sailer, S., Bolzano, K., Sandhofer, F., Spath, P., Braunsteiner, H. : Triglyceridspiegel und Insulinkon- zentration im Plasma nach oraler Glukosegabe bei Patienten mit primärer kohlenhydratinduzierter $\mathrm{Hy}$ pertriglyceridämie. Schweiz. med. Wschr. 98, 15121518 (1968)

44. Salaman, M.R., Robinson, D.S.: Clearing-factor lipase in adipose tissue. A medium in which the onzyme activity of tissues from starved rats increases in vitro. Biochem. J. 99, 640-647 (1966)

45. Schalch, D.S., Kipnis, D.M.: Abnormalities in carbohydrate tolerance associated with elevated plasma non-esterified fatty acids. J. clin. Invest. 44, 2010$2020(1965)$

46. Seyffert, W.R., Jr., Madison, L.L.: Physiologic effects of metabolic fuels on carbohydrate metabolism. I. Acute effect of elevation of plasma free fatty acids on hepatic glucose output, peripheral glucose utilization, serum insulin and plasma glucagon levels. Diabetes 16, $765-776(1967)$

47. Shafrir, E., Biale, Y.: Effect of experimental hypertriglyceridaemia on tissue and serum lipoprotein lipaseactivity. Europ. J. clin. Invest. 1, 19-24 (1970)

48. Steele, R.: In: "Tracer probes in steady state systems", p. 23. Springfield, Illinois: Charles C. Thomas 1971

49. Stout, R.W., Vallance-Owen, J.: Insulin and Atheroma. Lancet 1969 I, $1078-1080$

50. Winegrad, A.I.: In: Handbook of Physiology, p. 319 (Ed. Renold, A.E., Cahill, G.F.). Baltimore: Williams and Wilkins 1965

51. Wing, D.R., Robinson, D. S.: Clearing factor lipase in adipose tissue. A possible role of adenosine-3-5(cyclic)-monophosphate in the regulation of its activity. Biochem. J. 109, 841-849 (1968)

Prof. V. Wynn

Alexander Simpson Lab.

for Metabolic Research

St. Mary's Hospital Medical School

London W. 2.

Great Britain 